\title{
Apuntes críticos al psiquismo de la violencia de Byung-Chul Han
}

\section{Critical Notes on Byung-Chul Han's} Psyche of Violence

ROBERTO ISRAEL RODRÍGUEZ SORIANO UNIVERSIDAD AUTÓNOMA DEL ESTADO DE MORELOS | México

Contacto: calla_o@yahoo.com.mx

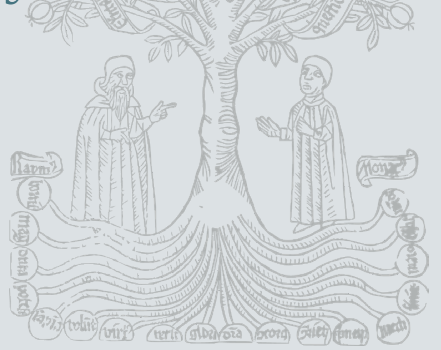

\begin{abstract}
Resumen
A lo largo de su obra filosófica, Byung-Chul Han desarrolla la noción de sociedad de rendimiento como concepto interpretativo y explicativo de las configuraciones sociales y culturales actuales. Lo que caracterizaría a la sociedad tardomoderna es que los sujetos se encuentran saturados de sí mismos; trabajan jornadas exhaustivas para cumplir exigencias que se ponen a sí mismos como el ideario de la búsqueda y consecución de la realización de sus vidas. Esta dinámica ha implicado que el ejercicio de la violencia se interiorice, haciendo que ésta se ejerza sobre sí mismo. Para Han, ha habido una transformación en la constitución psíquica que ha posibilitado que el deber, que imponía el ideal del yo sobre el yo, que era negatividad y que representaba un ejercicio de violencia desde el exterior hacia el sujeto, se transforme en poder. Ahora, supone Han, el ideal del yo, como elemento psíquico que definía la negatividad, se ha diluido o se ha fusionado con el yo. El sujeto ahora "más bien se obedece a sí mismo". Según su interpretación, el narcisismo sería lo que ahora definiría al sujeto de la sociedad del rendimiento. Sin embargo, la interpretación de Han sobre las implicaciones del deber y del poder en la relación del yo y del ideal del yo parece errónea a la luz de una relectura de la propuesta freudiana sobre la dialéctica y la tópica psíquica. En este trabajo se ofrecerán algunos argumentos para sostener esta tesis que pasan, en primer lugar, por la lectura de la hipótesis freudiana sobre las pulsiones sexuales y las pulsiones de muerte; en segundo lugar, por la relectura de la formulación freudiana de la tópica psíquica; $\mathrm{y}$, finalmente, por la idea de autonomía kantiana que supone Han en su argumentación y por la referencia al uso y la finalidad del panóptico benthamiano.
\end{abstract}

Palabras clave: rendimiento, control, autoexplotación, deber, poder, ideal del yo, Byung-Chul Han

\begin{abstract}
Throughout his philosophical work, Byung-Chul Han develops the notion of burnout society as an interpretative and explanatory concept of current social and cultural configurations. What would characterize modern-day society is that the subjects are saturated with themselves; they work exhaustive days to fulfill self-imposed demands like the ideology of the search and achievement of realizing their lives. This dynamic has meant that the exercise of violence is internalized by having it be exercised on itself. For Han, there has been a transformation in the psychic constitution that has made it possible for duty, which imposed the ideal of the I on the self, which was negativity and represented an exercise of violence from the outside towards the subject, to be transformed into power. Now, Han supposes, the ideal of the self, as a psychic element that defined negativity, has been diluted or merged with the self. The subject now "rather obeys himself." According to his interpretation, narcissism would be what now defines the subject of the performance society. However, Han's interpretation of the implications of duty and power in the relation of the self and the ideal of the self seems erroneous in light of a rereading of the Freudian proposal on the dialectic and psychic topic. In this paper, some arguments will be offered to support this thesis, which, first of all, goes through the reading of the Freudian hypothesis about sexual drives and death drives; for the rereading of the Freudian formulation of the psychic topic; for the idea of Kantian autonomy that Han supposes in his argument; and for the reference to the use and purpose of the Benthamian panoptic.
\end{abstract}

Keywords: burnout, control, self-exploitation, duty, power, ideal of the self, Byung-Chul Han 


\section{Introducción}

A lo largo de su obra filosófica, Byung-Chul Han desarrolla la noción de sociedad del rendimiento como concepto interpretativo y explicativo de las configuraciones sociales y culturales actuales. De acuerdo con esta noción, lo que caracteriza a la sociedad tardomoderna es que los sujetos se encuentran saturados de sí mismos, trabajan jornadas exhaustivas para cumplir exigencias que se ponen a sí mismos, tales como el ideario de la búsqueda y consecución de la realización de sus vidas. Esta dinámica ha implicado que el ejercicio de la violencia se interiorice, haciendo que ésta se ejerza sobre sí.

La sociedad del rendimiento se diferencia de la sociedad disciplinaria en la que el ideario es el "deber". Dice Han (2015):

La sociedad disciplinaria de Foucault, que consta de hospitales, psiquiátricos, cárceles, cuarteles y fábricas, ya no se corresponde con la sociedad de hoy en día. En su lugar se ha establecido desde hace tiempo otra completamente diferente, a saber: una sociedad de gimnasios, torres de oficinas, bancos, aviones, grandes centros comerciales y laboratorios genéticos. La sociedad del siglo XXI ya no es disciplinaria, sino una sociedad de rendimiento. Tampoco sus habitantes se llaman ya "sujetos de obediencia", sino "sujetos de rendimiento". Estos sujetos son emprendedores en sí mismos. Aquellos muros de las instalaciones disciplinarias, que delimitan, tienen un efecto arcaico. (35-36)

Han explica esta nueva situación usando formulaciones teóricas del psicoanálisis freudiano, según las cuales se ha desarrollado una transformación en la constitución psíquica que ha posibilitado que el deber, que imponía el ideal del yo sobre el yo, que era negatividad y que representaba un ejercicio de violencia desde el exterior hacia el sujeto, se transforme en poder. Ahora, el ideal del yo, como elemento psíquico que definía la negatividad, se ha diluido o se ha fusionado con el yo. El sujeto ahora "más bien se obedece a sí mismo" (Han, 2016a: 48). El narcisismo es lo que actualmente define al sujeto de la sociedad del rendimiento.

Sin embargo, la interpretación de Han sobre las implicaciones del deber y del poder en la relación del yo y del ideal del yo muestran varias inconsistencias de fondo que se evidencian, en primera instancia, a través de una lectura meticulosa de la propuesta psicoanalítica, freudiana y lacaniana, sobre la dialéctica y la tópica psíquica. En este trabajo se ofrecerán algunos argumentos para sostener esta tesis que pasa, en primer lugar, por la lectura de la hipótesis 
freudiana sobre las pulsiones sexuales y las pulsiones de muerte; en segundo lugar, por la relectura lacaniana de la formulación freudiana de la tópica psíquica; y, finalmente, por la idea de autonomía kantiana que supone Han en su argumentación y por la referencia al uso y la finalidad del panóptico benthamiano. Así pues, el objetivo de esta reflexión es hacer una revisión de los supuestos teóricos que asume Han, a la luz de una lectura crítica de sus mismos referentes, para mostrar que su propuesta tiene varias inconsistencias teóricas y argumentales graves que terminarían invalidando su distinción entre sociedades disciplinarias y sociedades de rendimiento.

\section{De la sociedad disciplinaria a la sociedad del rendimiento}

La sociedad del rendimiento se distingue de la sociedad disciplinaria, en la que el ideario era el deber. En el nuevo tipo de sociedad, propia del siglo xxI, se sustituye este ideario del deber por el poder (como efecto de la voluntad). En el proceso del tránsito de la una a la otra, como un desarrollo fundamental topológico, la violencia se interioriza. Esto significa que las tensiones destructivas ahora se disputan internamente en vez de descargarse hacia afuera (Han, 2016a: 19). Esto es debido a que las técnicas de dominación posibilitan que el sujeto (de obediencia) interiorice las instancias de dominación externa y las convierta en parte de su ser: ${ }^{1}$

De este modo, la dominación requiere un esfuerzo mucho menor para ejercitarse. La violencia simbólica también se sirve del automatismo del hábito. Se inscribe en las convicciones, en los modos de percepción y de conducta. A su vez, la violencia se naturaliza, mantiene el orden de dominación vigente sin ningún tipo de esfuerzo físico o material. También la técnica disciplinaria se vale de la internalización psíquica de las fuerzas. (Han, 2016a: 2)

\footnotetext{
1 Ivonne Natacha Pinzón (2019) plantea una pregunta interesante al respecto de la transformación de la moralidad en el tránsito de las sociedades disciplinarias a las del rendimiento en los términos en los que la plantea Han. La autora supone que la culpa, la mala conciencia y el resentimiento que describe Nietzsche en la Genealogía de la Moral siguen vigentes en la sociedad del rendimiento. La conciencia de los sujetos, dice, se encuentra enferma y ésta afecta no sólo a lo individual y a lo social (Pinzón, 2019: 310). El punto que parece interesante es que hay una aparente transformación de la moralidad en el tránsito de un tipo de sociedad a la otra. Sin embargo, ésta sigue recayendo en la idea del deber y de la culpa. Ambas instancias se generan y encuentran su estructura tópica en la configuración psíquica del conflicto entre el "yo" y el "sup 588189er yo" que, como se expondrá más adelante, no se transforman en lo absoluto en lo que Han supone un cambio estructural.
} 
Las técnicas de dominación son interiorizadas y vueltas parte del ser del sujeto. En este proceso, la violencia simbólica se sirve del automatismo del hábito; se inscribe en las convicciones perceptivas y conductuales. Así, la violencia se naturaliza a un grado extremo. Se posibilita que la dominación se logre sin ningún esfuerzo físico o mental: "por medio de una intervención discreta y delicada, penetra en las vías nerviosas y las fibras musculares del sujeto, sometiéndolo a coacciones e imperativos ortopédicos y neurológicos" (Han, 2016a: 2).

En este sentido, el sujeto de rendimiento no estaría ya sometido a nadie. Incluso el sujeto deja de ser tal, ya que queda libre de cualquier sujeción; ahora se vuelve un proyecto que se dirige hacia la propia explotación. La violencia, anteriormente dirigida y gestionada hacia el sujeto desde fuera y, a su vez, desde el sujeto hacia afuera (en el deber), ahora se interioriza y se dirige de sí hacia sí. La violencia externa dirigida hacia éste se vuelve laxa, tenue y sutil porque esa direccionalidad no es tan necesaria.

La sociedad disciplinaria es una sociedad de la negatividad; es decir, la define la prohibición, caracterizada por la obligación que trae consigo tanto el no poder como el deber. La sociedad del rendimiento se distinguiría, por su parte, por la transformación de la negatividad en positividad en la fórmula "puedo sin límites". Esta transformación genera un cambio en la producción de individuos: "Su negatividad [de la sociedad disciplinaria] genera locos y criminales. La sociedad de rendimiento, por el contrario, produce depresivos y fracasados" (Han, 2015: 37). Sin embargo, el paso de una forma de sociedad a otra se da a manera de una continuidad y no una ruptura. Esa continuidad se encuentra en la maximización de la producción. La prohibición que caracteriza a la sociedad disciplinaria alcanza su límite productivo debido al efecto negativo que produce un bloqueo e impide un crecimiento exponencial. Se hace necesario, para maximizar la producción, el cambio de paradigma al esquema del "poder hacer" - esto es, un cambio hacia la positividad-. La positividad genera un individuo más productivo y más rápido.

En La sociedad del cansancio, Han (2015: 41) afirma que con el incremento de la productividad no se da un rompimiento entre el deber y el poder, sino que más bien representa una continuidad. Sostiene, además, que en esta nueva sociedad lo que provoca la depresión por agotamiento, ${ }^{2}$ que es una de sus

${ }^{2}$ Han toma la idea de la depresión de Alain Ehrenberg. Este último supone que la depresión encuentra su éxito cuando el modelo disciplinario de gestión de las conductas (prohibiciones asignadas a las clases sociales y a los sexos) cede ante las normas que incitan a cada uno a la iniciativa individual de asumir 
características definitorias, no es el imperativo de pertenecerse sólo a sí mismo, sino a la presión del rendimiento. Ésta es una forma de violencia sistémica. El proceso que posibilita el paso de una sociedad disciplinaria a una sociedad de rendimiento es pensado por Han a partir de la instancia de constitución psíquica del individuo, específicamente en la transformación dialéctica entre el yo y el superyó originalmente propuesta por Sigmund Freud.

\section{Del deber al poder de la sociedad del rendimiento}

Como se ha señalado anteriormente, Han supone que en la sociedad actual hay una transformación del deber al poder. Esto se explicaría debido a que las máximas del sujeto de rendimiento ya no son la obediencia, la ley y el complimiento del deber, sino que ahora son la libertad, el placer y el entretenimiento. En esta sociedad tardomoderna, habría un desprendimiento de la negación de la prohibición y del mandato, de modo que se concibe a sí misma como una sociedad de libertad (Han, 2016a: 45), para lo cual recurre a la caracterización de Freud del aparato psíquico del sujeto de la sociedad disciplinaria como aquella que "se rige por la negación, la represión y el miedo a la transgresión" (Han, 2016a: 46). El yo es "la verdadera residencia de la angustia'. Tiene miedo del gran sujeto" (Han, 2016a: 46). En cambio, dice Han, el sujeto del rendimiento es pobre en negación; es el sujeto de la afirmación. Esto es así porque ya no tiene inconsciente toda vez que se basa en la negación de la negatividad, lo cual supone que el yo no se rige ya por el deber que le impone el ideal del yo, sino por la positividad del puedo. Este sujeto se desborda de narcisismo porque hay una desvinculación con el otro (que es un lugar

esas normas como propias. La consecuencia es que la responsabilidad de las propias vidas se aloja en cada uno, así como en el "nosotros colectivo". De esta forma se presenta lo que Ehrenberg llama "una enfermedad de la responsabilidad" en la que domina un sentimiento de insuficiencia ya que hay un sentimiento profundo de que no se está a la altura (Ehrenberg, 2000: 12-13). Así, el individuo se vuelve un soberano de sí mismo; a uno mismo es a quien se tiene que rendir cuentas. Dice: "El derecho a elegir la propia vida y la conminación a convertirse en uno mismo ponen a la individualidad en un movimiento permanente. [...] el equilibrio entre lo permitido y lo prohibido declina en provecho de un desgarramiento entre lo posible y lo imposible. [...] el lugar de la disciplina en los modos de regulación de la relación individuo-sociedad se ha reducido. Se apela menos al recurso de la obediencia disciplinaria que a la decisión y a la iniciativa personal. En lugar de que una persona sea puesta en acción por una orden exterior (o por la conformidad a la ley), se hace necesario apoyarse en sus resortes internos, recurrir a sus competencias mentales. La noción de proyecto, de motivación, de comunicación son las normas de hoy. [...] Los actores públicos y privados se apoyan en estas nociones; se las utiliza tanto en la gestión de las empresas como en las políticas de reinserción" (Ehrenberg, 2000: 16). 
ocupado por Dios, el soberano o el padre) y la afectividad se retrotrae al sujeto mismo cuya gratificación, por su propia constitución psíquica en la transformación del sujeto de rendimiento, resulta inalcanzable, pues ya no hay la negatividad requerida para la satisfacción del cumplimiento: "Quien se ama a sí mismo, se posiciona claramente contra el otro. En el narcisismo se desdibuja la frontera con el otro. Quien sufre un trastorno narcisista se hunde en sí mismo. Si se pierde del todo la relación con el otro, no se puede construir una imagen sólida del yo" (Han, 2016a: 50). A esto se le suma la naturaleza del mismo sistema productivo que implica un continuum eterno. La imposición social que se hace al sujeto, por su desvinculación con el otro y por la naturaleza de la producción capitalista por la positividad, le genera un sentimiento de nunca haber alcanzado su meta.

Han afirma que la sociedad de rendimiento actual, regida por la idea de libertad y desregulación, desarma los obstáculos y las prohibiciones que constituyen la sociedad disciplinaria. Esto impacta en el aumento del rendimiento. Parece importante señalar que, en consonancia con el desarrollo teórico anterior, Han supone que el concepto de biopolítica que desarrolló Foucault, como forma del poder político para el disciplinamiento a través de un sistema de normas y prohibiciones que coaccionan calculadamente cada parte del cuerpo y la mente para crear un sujeto obediente, no sería útil para interpretar a las sociedades tardomodernas toda vez que la coacción proviene de fuera del sujeto. Para ello propone el concepto de psicopolítica, el cual se configura como una estrategia de control que se basa en la explotación de la psique a través de la gestión de las emociones, los deseos, los anhelos y los sentimientos de los sujetos por medio de mecanismos de manipulación psíquica donde cada uno es su propio capataz que promueve la obediencia y la autoexplotación (Han, 2014: 20). En la fase actual del desarrollo del capitalismo, lo biológico, lo somático y lo corporal se vuelven aspectos secundarios para la explotación:

El cuerpo como fuerza productiva ya no es tan central como en la sociedad disciplinaria biopolítica. Para incrementar la productividad, no se superan resistencias corporales, sino que se optimizan procesos psíquicos y mentales. El disciplinamiento corporal cede ante la optimización mental. Así, el neuroenhancement se distingue fundamentalmente de las técnicas disciplinarias psiquiátricas. (Han, 2014, 23) 
Como se apuntó anteriormente, estos últimos planteamientos parten de los supuestos teóricos que se han desarrollado más arriba, los cuales tienen varias inconsistencias teóricas que se analizarán a continuación. ${ }^{3}$

\section{Pulsiones}

Para comenzar a hacer las anotaciones críticas a las tesis de Han, es necesario reflexionar sobre las pulsiones puesto que esto permitiría comprender cómo se origina la violencia que, en su caracterización del sujeto del rendimiento, se ejerce sobre sí. Con esta motivación se ofrecerá una amplia reflexión sobre los aspectos teóricos del psicoanálisis que permitirán trazar las líneas psicogenéticas de la violencia. El recorrido podría parecer extenso y digresivo. Sin embargo, no lo es. Se hace necesario toda vez que Han no hace explícitos muchos de sus supuestos, cuando es ahí donde pueden ubicarse los errores teóricos de su propuesta.

Freud supone que el aparato anímico del ser humano está regido por energías pulsionales que tienen como objetivo una satisfacción placentera (principio de placer). Sin embargo, ante la imposibilidad de satisfacción, debido a mecanismos psíquicos que se definen por el principio de realidad, como el de represión, no encuentran la consecución de su fin, generando una fuente de displacer (Freud, 2004a: 10). El yo consciente y el preconsciente requieren ahorrarse el displacer porque éste produce un gasto psico-energético grande que puede afectar gravemente el equilibrio en el aparato psíquico que gobierna la vida del individuo. Uno de los mecanismos para evitar el displacer es el de bloquear, en el mayor grado posible, los estímulos externos.

\footnotetext{
3 Una de las rutas críticas con respecto de la psicopolítica como superación de la biopolítica que plantea Han, que en este trabajo no se desarrollará por cuestión de la intención del mismo, se dirige a la relación del cuerpo y psique. Como lo ha señalado Alejandro Recio Satre (2019), Han hace una separación que no alcanza a justificar entre la psique y el cuerpo. Dice Recio Sastre (2019): "su consideración [de Han] de 'psicopoder' no se origina en la inmanencia corporal sino en la inmanencia de la psique, como si fuera algo diferente del cuerpo, como si no hubiera una síntesis originaria en la que psique y cuerpo aparecen unidos e indistintos el uno del otro. Al ceñirse a la inmanencia psíquica, Han no está hablando de un poder originario a la vida en su totalidad, ni mucho menos de un 'poder puro' - suponiendo que lo hubiera-. Han está suponiendo de la clásica división, tanto antigua como moderna, que separa la corporalidad de otro inmaterial, ese otro inmaterial que bien podría ser considerado alma, espíritu, mente, psique, etc." (251). Este señalamiento resulta importante en la medida en que la construcción de la subjetividad desde la perspectiva biopolítica no permite trazar esa escisión que en la propuesta de la psicopolítica de Han es muy arbitraria.
} 
Los procesos psíquicos de defensa pueden llevar a una compulsión de repetición; es decir, se lleva a una repetición de la vivencia displacentera, ya que esa misma repetición permite el dominio (el control) más radical sobre la impresión intensa recibida y permite asumir la vivencia de un modo meramente pasivo (Freud, 2004a: 36). Habría así dos tipos de pulsiones: las que buscan la sobrevivencia del organismo (sexuales) y las que buscan terminar con la vida para así terminar con los estímulos displacenteros que implica el vivir. Estas dos pulsiones estarían presentes en una constante lucha.

Por un lado, las pulsiones pueden buscar suprimir la excitación displacentera, produciendo un efecto hacia el exterior del organismo, a través de su propia agencia, o pueden buscar producir un efecto hacia su interior para que, a través de un efecto, cese la excitación psíquica. Entonces, todas las pulsiones y los medios de satisfacción pulsional son negativos toda vez que se contraponen a un estímulo externo. Nunca una pulsión puede ser positividad como lo asume Han. Las pulsiones siempre se juegan en la negatividad, ya sea externa o interna (que en realidad es una internalización de lo externo en, por ejemplo, el mandato al yo).

En este sentido, y bajo la premisa freudiana, el deseo y la apetencia de la vida como parte de una naturaleza humana tienen que ser vistas a la luz de su compleja dinámica con el deseo y la apetencia de la muerte. Es importante explicitar este entramado teórico ya que sólo a través de la comprensión del desarrollo del conflicto pulsional se puede entender el tránsito que plantea Han desde las sociedades disciplinarias a las sociedades de rendimiento.

En sus escritos de psicología social, Freud desarrolló la idea de que el trabajo cultural tiene la finalidad de evitar la disolución de la sociedad a partir de una renuncia de la satisfacción pulsional, lo cual supone que en toda sociedad, de la misma manera que en los individuos, se encuentra latente una pulsión destructiva originaria. Así, la cultura se presenta como un impulso de "conservación" ("al servicio de Eros"), contrario a esa pulsión destructiva, intentando mantener cohesionados a los individuos, a las familias, a las etnias, a los pueblos, a las naciones y, en términos generales, a la humanidad. La vida social y la cultura imponen sacrificios que tienen que ver con la renuncia a la satisfacción pulsional. Freud supone que el impulso destructivo pulsional es interiorizado y devuelto hacia el yo propio. Éste es recogido por una parte del yo, que se contrapone al resto como superyó, como conciencia moral. La "conciencia de culpa" sería el resultado entre la tensión del superyó y del yo sometido, que es exteriorizada como "necesidad 
de castigo" (Freud, 2004b: 120). La referencia a Freud es importante por su teorización sobre la fuerza destructiva que subyace a la sociedad y sobre los mecanismos sublimatorios, coercitivos y punitivos que la sociedad, a través del trabajo cultural, busca establecer con el fin de resguardar la vida individual y social (Freud, 2004a: 60). Aquí adquiere pleno sentido lo antes referido sobre el conflicto pulsional.

Ahora bien, las implicaciones de todo esto para la propuesta de Han es que si las pulsiones no tuvieran en frente suyo una negatividad, que le viene dada tanto de la materialidad del mundo como de la exigencia del deber que establece el superyó (el principio de realidad), si todo fuera positividad como él lo supone, no habría insatisfacción alguna. Los sujetos no sufrirían depresión ni síntomas o enfermedades que se supone que caracterizan a la sociedad del rendimiento. Las pulsiones alcanzarían su objetivo, que es la satisfacción. Por lo tanto, no podría originarse la violencia. Pero, lo que más bien sucede es que sigue habiendo una insatisfacción pulsional que viene dada de una negatividad. La negatividad que supone el superyó o el ideal del yo, cambia de forma y se interioriza sin desaparecer. La adicción al trabajo y a la autoexplotación sólo puede explicarse por la necesidad de la satisfacción pulsional, la cual sólo encuentra sentido en la negatividad. Y la violencia que el sujeto ejerce sobre sí, sólo puede explicarse a través de las pulsiones de muerte que se generan esencialmente en la negatividad.

\section{La conformación del ideal del yo}

El otro elemento crítico a considerar es la lectura que hace Han de la constitución psíquica del sujeto. La importancia de esta reflexión para la revisión de la propuesta de Han radica en que el ideal del yo en el desarrollo teórico de Freud es una instancia psíquica que se configura por un mandato externo que se interioriza, pero que no deja de ser una externa y por lo tanto la exigencia de éste nunca es interior y "propia" o "autónoma" aunque se interiorice, como lo supone Han en su idea de autoexigencia.

En su trabajo El yo y el ello, Freud (2001: 27) establecía la caracterización del yo y del ello definiendo al primero como la parte racional de la psique y al segundo como la parte pasional. El yo depende de la conciencia y gobierna los accesos a la motilidad - es decir, a la descarga de las excitaciones en el mundo exterior - y es la instancia anímica que ejerce control sobre los procesos 
de percepción. El yo juega un papel determinante en los procesos de represión. El yo controla y discrimina las "aspiraciones anímicas" que deben excluirse de la conciencia (Freud, 2001: 19).

E1 yo sufre también el influjo de otra instancia anímica que se conforma a lo largo de la maduración psíquica del individuo, específicamente en la fase sexual gobernada por el complejo de Edipo, a saber, el ideal del yo. En el caso concreto del niño varón, Freud (2001: 34) expone el siguiente proceso: 1) el niño desarrolla una investidura de objeto hacia la madre; 2) el niño se apodera del padre a través de identificación; 3) ambos vínculos van de la mano, hasta que, por el refuerzo de los deseos sexuales hacia la madre, y por la percepción de que el padre es un obstáculo para estos deseo, nace el complejo de Edipo; 4) la identificación-padre adquiere un carácter hostil y nace el deseo de aniquilar al padre para sustituirlo; 5) a partir de este momento su relación con el padre es ambivalente; 6) posteriormente, con la superación del complejo de Edipo, la investidura de objeto de la madre debe de ser reasignada, lo cual puede tener dos posibles tipos diferentes de reemplazo: una identificación con la madre o un refuerzo de la identificación-padre.

De esta forma se constituye el superyó o el yo-ideal. En su carácter de ideal se impone tanto con la exigencia "así debes ser" como "así no te es lícito ser". Posteriormente, el superyó mantendrá el carácter del padre, y entre más intenso fue el complejo de Edipo y más rápido se produjo su represión (por influencia de la autoridad, de la doctrina religiosa, de la enseñanza, la lectura) ejercerá su imperio y se convertirá en la conciencia moral (Freud, 2001: 35). El ideal del yo (o superyó) se caracteriza como la esencia de la autoridad abstracta que se impone al individuo en su identificación con la voz del deber. En este sentido, el ideal del yo se conforma por la autoridad que la cultura impone al individuo. Sin embargo, se entrevé un problema: la constitución del yo está marcada por la serie de desplazamientos que se originan en el proceso de sustitución en la superación del complejo de Edipo. Sin embargo, podría preguntarse cuáles son los contenidos de esos desplazamientos y sustituciones. Jacques Lacan (1985: 213) dirá que esos desplazamientos corresponden al orden del lenguaje, el cual se configura como la autoridad. El intercambio simbólico, es decir, el lenguaje, es lo que vincula entre sí a los seres humanos en tanto que le permite construir alguna identidad al sujeto. Este orden simbólico, paradójicamente, preexiste al sujeto y es el de la cultura (Aguilar, 1984: 64). La identidad tiene que intentar completarse a través del Otro, es decir, en el "Ideal de yo". 
La exigencia del Otro, del "Ideal del yo", viene a través del lenguaje. Desde antes del nacimiento el sujeto está inscrito en el lenguaje cuya exigencia está representada ya desde la imposición de un nombre propio (Lacan, 2005: 475). El sujeto nace inserto en la tradición que instaura ese discurso; es decir, se encuentra inserto en las estructuras "elementales de la cultura". ${ }^{4}$

Han supone que el hecho de que no haya Otro (u otros) que ejerza el mandato de manera externa sobre el sujeto implicaría que la coacción externa desaparece y, por lo tanto, el mandato de deber desaparece y se transforma en poder. Sin embargo, como dice Lacan, la interiorización del mandato del Otro se ha depositado a través del lenguaje, desde siempre, en la psique del sujeto, que se manifiesta tempranamente en las identidades sexuales, religiosas, físicas, culturales, etcétera. El individuo que supone Han no podría existir. Tendría que ser un no-sujeto, como él mismo lo señala. El poder que supone como diferente al deber es simplemente otra cara de éste. E1 "yo puedo" sigue siendo una afirmación del sujeto frente a la negatividad del "no puedo". Y ambos sólo adquieren sentido frente al mandato del Otro, frente al deber. Entonces, no es que la violencia ahora se interiorice; es que siempre ha estado interiorizada ya sea activa o pasivamente. La violencia que el sujeto de la sociedad del rendimiento ejerce sobre sí mismo responde a la misma lógica del deber. Se violenta porque no cumple con el deber de poder.

En su obra Sobre el poder, Han (2017) supone la existencia de un poder libre que indica que el otro obedece libremente al yo. Es decir, es un poder que se origina en la libertad conferida a través de la persuasión y no en la coacción, logrando que el otro haga la voluntad del yo asumiendo este acto como una decisión propia:

\footnotetext{
${ }^{4}$ Lacan reformula el planteamiento saussuriano en que se designaba al signo lingüístico como una entidad psíquica de dos caras en que al significante le correspondía un solo signo ( $\mathrm{S} / \mathrm{s}=$ significante sobre significado) (Saussure, 1945: 127-130). Para Lacan, el significante no funciona como una representación del significado. El sentido es producido por los significantes; es dado desde el significante hacia el significado. De esta manera el significante anticipa siempre el sentido que despliega este mismo. Entonces, lo que crea el sentido en cada caso es el diferente significante. El significante manifiesta la presencia de una diferencia haciendo imposible la conexión entre los signos y las cosas (Stavrakakis, 2007: 12). El significado pertenece al registro de lo real, pero eso real se resiste a la simbolización. En otras palabras, es lo imposible para el sujeto; implica ausencia. Ésta tiene que ser compensada para que la significación adquiera coherencia. Así, esta ausencia del significado es el motivo de la necesidad de una transferencia del significado. La simbolización tiene por consecuencia el que la identidad del sujeto tenga que ser adquirida a través de una mediación. Ésta es la falta que hace imposible la adquisición de una identidad estable.
} 
El poder capacita al yo para recobrarse a sí mismo en el otro. Genera una continuidad del sí mismo. El yo realiza en el otro sus propias decisiones. Con ello el yo se continúa en el otro. El poder proporciona al otro espacios que son los suyos, y en los que, pese a la presencia del otro, es capaz de recobrarse a sí mismo en el otro. El poder proporciona al otro espacios que son los suyos, y en los que, pese a la presencia del otro, es capaz de recobrarse a sí mismo. Capacita al soberano a regresar a sí mismo en el otro. (Han, 2017: 18)

Justamente ésta es la idea sobre la que Han supone que el deber y su negatividad pueden reemplazar al poder como positividad en la forma de una especie de auto-mandato. Sin embargo, insistiendo en los argumentos anteriormente desarrollados, la coacción no desaparece y el poder sobre otra persona, aún en la forma en la que lo describe Han, sigue siendo coactivo en la medida en que sigue siendo una imposición, ya sea asumida como propia o no. Justamente lo que muestra el desarrollo teórico psicoanalítico es que el yo siempre actúa coactivamente por influjo del ideal del yo en un proceso psíquico de negatividad. Independientemente de que el sujeto asuma como propia una determinación por persuasión, están ya siempre en juego los procesos psíquicos internos de coacción que lo impelen a asumir como propia la decisión de hacer, y esto remite a la noción de autonomía. La transformación del pensamiento del proceso que asume Han no es en realidad una transformación sustancial; más bien es de forma. El aumento aparente de libertad no produce en realidad libertad, ni poder, sino que es más bien un mecanismo de dominación más efectivo cuanto más silencioso e invisible es (Cruz Ortiz de Landázuri, 2017: 197).

\section{La autonomía kantiana}

Parte de los errores teóricos en los que incurre Han se deben a su diálogo con Kant y su noción de autonomía. Acepta que para Kant la conciencia moral ocupa la posición del superyó, sometiendo así al sujeto a una violencia moral (Han, 2015: 46). Acepta que habría una escisión de la persona en un doble sí mismo que se manifiesta en juez y parte al mismo tiempo y que el actuar éticamente correcto produce una satisfacción (Han, 2015: 47). Sin embargo, en la noción de autonomía kantiana la razón juega las veces de principio rector, que es lo que objetiva al imperativo ético. La razón kantiana no se asemeja en 
nada a la formulación teórica freudiana, como lo supone Han. La autonomía kantiana se cierra sobre un sujeto que está desvestido de su materialidad, sobre un sujeto monádico cuya única relación ética con otros sujetos es su coparticipación en la racionalidad. El nomos le viene de sí mismo por su constitución antropológica. El punto es que el sujeto ético kantiano se acerca mucho más al sujeto del rendimiento de Han que al sujeto disciplinario.

Een la Metafísica de las costumbres, Kant rechaza una moral fundamentada empíricamente, así como una ética de fines al modo del utilitarismo. Por un lado, critica que la significación moral sea determinada por los efectos del acto; por otro lado, critica que se fie en un fin supremo, tales como la felicidad o el placer, para determinar el valor del acto moral. En ambos casos se está prescindiendo de propósitos y se está soportando en los fines. La teoría ética kantiana supone una teleología del acto ético, donde el acto moral persigue un valor, el valor máximo, el valor de la humanidad. Se debe actuar de acuerdo con éste, de manera que el actuar por deber es hacerlo de manera que las acciones expresan el valor de la humanidad. En la argumentación de Kant, el concepto de buena voluntad permite dotar de un carácter ético al acto moral, debido a que la buena voluntad vuelve a su querer como aquello que la hace buena de suyo. En otras palabras, la buena voluntad no es tal por un carácter teleológico o utilitarista, sino por sí misma (Kant, 2012: 67). Así, la Razón adquiere el papel primordial de ser rectora de la voluntad para generar una voluntad buena en sí misma y no como medio para otro propósito. Kant (2012: 68) enfatiza que la razón no es la herramienta o medio para la consecución de un fin, sino que desempeña la función de dirigir, en su cualidad de capacidad práctica, a la voluntad como bien supremo y como condición de cualquier otro bien.

La razón desempeña esta función a través del deber, el cual determina la acción y le da su cualidad ética al ser la máxima a partir de la cual se decide la acción:

Así pues, ¿dónde puede residir dicho valor, si éste no debe subsistir en la voluntad con relación a su efecto esperado? No puede residir sino en el principio de la voluntad, al margen de los fines que pueden ser producidos por tales acciones; pues la voluntad está en medio de una encrucijada, entre su principio a priori, que es formal y su móvil a posteriori, que es material; y como, sin embargo ha de quedar determinada por algo, tendrá que verse determinada por el principio formal del querer en general, si una acción tiene lugar por deber, puesto que se le ha sustraído todo principio material. (Kant, 2012: 74) 
Para Kant el valor moral de la acción no se encuentra en el propósito que se intenta alcanzar sino en la máxima que lo decidió y que determinó la acción; no depende del objeto de la acción, sino del principio del querer a partir del cual se ha sucedido la acción. Con esto, el valor no depende en el principio de voluntad sino del principio formal que la impele a actuar, es decir, del deber, lo cual significa que una acción es necesaria de acuerdo con una ley. Entonces, la ley se asume como una representación en sí misma que sólo puede ser realizada por seres racionales. Esta motiva a la voluntad hacia el "bien moral", pues la ley no debe estar dirigida por un fin teleológico, sino que debe estar dirigida hacia la acción de la voluntad de una manera universal que debe servir como su único principio. Kant (2012) establece la proposición "yo nunca debo proceder de otro modo salvo que pueda querer también ver convertida en ley universal a mi máxima [práctica]" (91). De esta manera, Kant finca la legitimidad general del deber en el actuar en el que coincide la razón y el enjuiciamiento práctico ante el cual impone el principio referido (López de Lizaga, 2008: 110). La razón humana tiene, a priori, las determinaciones del acto que tienden hacia la concreción del acto bueno. Sólo el ser humano, el ser racional, tiene la capacidad de obrar según las representaciones de la ley, porque posee voluntad en cuanto razón práctica (Kant, 2012: 91).

Ahora bien, la autonomía de la voluntad es para Kant el único principio que puede fincar leyes morales en contraposición a la heteronomía, la cual es contraria a la moralidad de la voluntad. El único principio de la moralidad consistiría en la independencia de la determinación objetiva. Así, la ley moral no expresa nada más que la autonomía de la razón práctica, la libertad (Kant, 2011: 59). De este modo, Han se equivoca al suponer que para Kant el acto ético está soportado por algo exterior al sujeto, pues éste viene dado, más bien, por la racionalidad humana que sería intrínseca al ser humano.

\section{El panóptico}

El panóptico, ${ }^{5}$ que Han utiliza para caracterizar a la sociedad de la transparencia, ejemplifica bien el acto disciplinar como un proceso que logra sujetos

\footnotetext{
5 Foucault (2005) resume sus características de la siguiente forma: "El Panóptico de Bentham es la figura arquitectónica de esta composición. Conocido es su principio: en la periferia, una construcción en forma de anillo; en el centro, una torre, ésta, con anchas ventanas que se abren en la cara interior del anillo. La construcción periférica está dividida en celdas, cada una de las cuales atraviesa toda la anchura de
} 
disciplinados, sujetos que no por el hecho de estar disciplinados prescinden de la coacción: la requieren de manera permanente, consistente y sistemática. Esa coacción viene de un deber interiorizado efecto del proceso disciplinar. El rendimiento sólo es posible por y a través de la disciplina, de la misma forma que la autoexplotación. Jeremy Bentham diseñó el panóptico con intenciones disciplinarias: "reúne [...] la seguridad, la sabiduría, la salubridad, la comodidad, la economía, y la facilidad de corregir el carácter y los principios morales de los presos, es decir, de quitarles la voluntad de volver a delinquir" (Bentham, 1979: 82). Bentham presentaba su invención para ser implementada en las prisiones. Sin embargo, hace explícito que ésta no sólo tendría efecto en los prisioneros en los que se buscaba una reforma moral, sino que también estaba pensada para los carceleros: "Una de las grandes ventajas colaterales de este plan es la de poner a los subinspectores y a los subalternos de toda especie bajo la misma inspección que a los presos, de manera que nada pueda hacer que no vea el inspector en jefe" (Bentham, 1979: 37). Esto es significativo porque el ejercicio del disciplinar aplica, de una u otra manera, a todos los sujetos. En otra parte, Bentham (1979) señala como una ventaja del panóptico "la convicción de que viven y obran incesantemente bajo la inspección perfecta de un hombre interesado en toda su conducta" (75). Esto, justamente, es la consecución de la disciplina.

Michel Foucault (2005) señalaba que el mayor efecto del panóptico era el de inducir en el detenido un estado consciente y permanente de visibilidad que garantiza el funcionamiento automático del poder: "Que la perfección del poder tienda a volver inútil la actualidad de su ejercicio; que este aparato arquitectónico sea una máquina de crear y de sostener una relación de poder independientemente de aquel que lo ejerce; en suma que los detenidos se hallen insertos en una situación de poder de la que ellos mismos son los portadores" (205). Disciplinar es un proceso continuo a través del cual el individuo es moldeado, y posteriormente, en la medida en que avanza el proceso, él mismo moldea su comportamiento, cada vez más, de acuerdo con las pautas que se le están imponiendo acorde con el fin específico de ser controlado, hasta que llega un momento en el que ya no es necesario el efecto de disciplinar

la construcción. Tiene dos ventanas, una que da al interior, correspondiente a las ventanas de la torre, y de una parte a otra. Basta entonces situar un vigilante en la torre central y encerrar en cada celda a un loco, un enfermo, un condenado, un obrero o un escolar. Por el efecto de la contraluz, se pueden percibir desde la torre, recortándose perfectamente sobre la luz, las pequeñas siluetas cautivas en las celdas de la periferia. [...] El dispositivo panóptico dispone unas unidades especiales que permiten ver sin cesar y reconocer el punto" (203). 
como imposición exterior. Esto es así porque ya ha sido disciplinado y ha incorporado como propia y autónoma la exigencia que antes se veía como coercitiva. Sin embargo, el efecto de disciplinar debe ser constante. El hecho de que la imposición pase del exterior al interior no significa que la exigencia (fuerza) se extinga. Así, el efecto disciplinar del panóptico hace que el sujeto ya no necesite siquiera un vigilante (lo mismo que una cámara de vigilancia no necesita estar prendida o servir para lograr su efecto). La sensación de que la torre tiene un vigilante es más que suficiente para que el efecto disciplinar deseado se logre. El proceso disciplinar externo culmina en la interiorización de la exigencia. Sin embargo, aunque el sujeto la incorpore como propia, la exigencia sigue siendo una coerción que se origina en una interpelación externa a través de la interiorización del deber.

Han (2016b) plantea que en la sociedad de transparencia, ${ }^{6}$ que se corresponde con la sociedad del rendimiento y que sería posterior a la sociedad disciplinar, el panóptico se vuelve fundamental: "con la ayuda de una técnica refinada se despierta la ilusión de una vigilancia permanente" (44). Sin embargo, según él, hay un cambio sustancial en el efecto: "los moradores del panóptico de Bentham son conscientes de la presencia constante del vigilante, los que habitan en el panóptico digital se creen que están en libertad" (Han, 2016b: 44). La esencia del panóptico es el control. Si esta intención desaparece, entonces, el panóptico se vuelve inservible. El hecho de que el poder se descentre no significa que deje de estar presente como agente activo.

Michel Foucault (1999), indagando sobre la transformación de la representación de la Época Clásica al periodo posterior, la "Época del Hombre" (Modernidad), a partir de su análisis del cuadro Las Meninas, deduce que hubo un cambio de la representación en la ubicuidad del poder soberano que deja de estar en el centro: el soberano está descentrado. El espectador es quien tiene que reconfigurar el cuadro asumiendo el poder soberano (el principio de la democracia). El espectador, en su perspectiva, es quien se sitúa en el lugar del soberano y ejerce un poder determinado como propio. Sin embargo, esto es efecto solamente de la perspectiva. Es una ilusión. El poder soberano sigue

\footnotetext{
${ }^{6}$ Dice Han (2016b: 20) que lo que caracterizaría a la transparencia sería una coacción sistemática que busca apoderarse de las acciones sociales que pueden producir sentido y las vuelve uniformes, operacionales y optimizadas. Se logra esto despojándolas de negatividad, negando cualquier forma de alteridad. La sociedad de la transparencia tiene un carácter totalizador en la medida en que iguala y totaliza al quitar a cualquier contenido cultural su diferencia.
} 
siendo exterior al espectador y está escondido y camuflado en el juego de perspectivas.

El poder político, soberano, se conforma y constituye a partir de una representación que ubica a quien, en términos teóricos, pertenece el poder político, a partir de la representación de un ente abstracto que puede adquirir múltiples formas. ${ }^{7}$ El efecto y acto de ese poder político es resultado de una representación. La democracia moderna, a partir de sus procedimientos representativos, se vuelve un juego de representaciones que descentran la ubicuidad del poder político soberano, haciendo a su vez imposible, o por lo menos sumamente dificultoso, ubicar concretamente a quien ejerce ese poder soberano. No obstante, ahí está: el ejercicio del poder y de la violencia no vienen enteramente del interior del sujeto, como lo supone Han. El poder soberano sigue ejerciendo su poder externamente, reafirmándolo en el interior del sujeto bajo la ilusión, efecto de la perspectiva, de que él es autónomo y soberano de sí y de su actuar y de que el mandato viene de sí mismo.

\section{Consideraciones finales}

Para Han, el sujeto de rendimiento no se dedica al trabajo por obligación y sus máximas son "la libertad, el placer y el entretenimiento" (2016a: 48). Sin embargo, las máximas se establecen desde un deber investido por la forma del poder. El poder del que Han habla tiene una ambivalencia: poder producir y poder consumir. Las dos formas son complementarias. La ilusión capitalista, con el elemento central de la violencia infringida sobre los sujetos y que los sujetos ejercen sobre sí mismos, es la libertad y la autodeterminación en los procesos de producción y de consumo - una libertad que resulta como efecto de la interiorización del mandato en el mantra "yo puedo" - . El placer y el entretenimiento son imperativos del consumo y de la producción en la lógica D-M-D+. ${ }^{8}$ Entonces, la dinámica de las sociedades modernas no responde

\footnotetext{
7 En el caso de la representación de Velázquez, se trata del rey, pero esta figura puede ser cualquier otra: Estado, Nación, Familia, etcétera.

8 La producción mercantil, que es inherente al capitalismo, origina dinámicas de consumo que buscan satisfacer necesidades basadas en el valor de cambio, generadas en configuraciones ideológicas que asumen a los bienes de consumo y de producción desligados de los procesos sociales productivos. La idea de libertad se subsume a la lógica de consumo que lleva implícita la producción de mercancía capaz de generar un plusvalor en el proceso de intercambio y de consumo. Uno de los mecanismos de control más efectivos que configuran la subjetividad basada en el rendimiento y la productividad es el consumo porque todas sus fuerzas físicas y psíquicas pueden encaminarse a este fin.
} 
a lo lógica que describe Han; sigue respondiendo esencialmente a la lógica de sociedades disciplinares en las que la violencia sigue ejerciéndose desde fuera hacia dentro a través de la internalización de esta y de la asunción de la autonomía para administrarla y gestionarla.

\section{Referencias bibliográficas}

Aguilar, Mariflor. (1984). Teoría de la ideología. UNAM.

Bentham, Jeremias. (1979). El Panóptico (Ramón Salas, Trad.). Las Ediciones del Piqueta.

CRUZ ORTIZ De LANDÁZURI, Manuel. (2017). "De la biopolítica a la psicopolítica en el pensamiento de Byung-Chul Han". Athenea Digital. Revista de Pensamiento e Investigación Social, 17(1), 187-203. https://doi.org/10.5565/rev/athenea.1782

EHrEnBerg, Alain. (2000). La fatiga de ser uno mismo. Depresión y fatiga (Rogelio C. Pardes, Trad.). Ediciones Nueva Visión.

FOUCAULT, Michael. (1999). Las palabras y las cosas. Una arqueología de las ciencias humanas. (Elsa Cecilia Frost, Trad.). Siglo XXI.

FOUCAULT, Michael. (2005). Vigilar y castigar. Nacimiento de la prisión. (Aurelio Garzón del Camino, Trad.). Siglo XXI.

FreUd, Sigmund. (2001). "El yo y el ello". En Obras completas (Vol. 19, 1-66; José Luis Etcheverry, Trad.). Amorortu.

FREUD, Sigmund. (2004a). "Más allá del principio de placer". En Obras completas (Vol. 18, 1-136; José Luis Etcheverry, Trad.). Amorrortu.

FREUD, Sigmund. (2004b). "El malestar de la cultura". En Obras completas (Vol. 21, 57-141; José Luis Etcheverry, Trad.). Amorrortu.

HAN, Byung-Chul. (2012). La sociedad del cansancio (Arantzazu Saratxaga Arregi, Trad.). Herder.

HAN, Byung-Chul. (2014). Psicopolitica. Neoliberalismo y nuevas técnicas de poder (Alfredo Bergés Herder, Trad.). Herder.

HAN, Byung-Chul. (2016a). Topología de la violencia (Paula Kuffer, Trad.). Herder.

HAN, Byung-Chul. (2016b). La sociedad de la transparencia (Raúl Gabas Pallás, Trad.). Herder.

HAN, Byung-Chul (2017). Sobre el poder (Alberto Ciria, Trad.). Herder. 
KANT, Immanuel. (2011). Crítica de la razón práctica (Dulce María Granja Castro, Trad.). UNAM; UAM; Fondo de Cultura Económica.

KANT, Immanuel. (2012). Fundamentación para una metafísica de las costumbres (Roberto R. Aramayo, Trad.). Alianza Editorial.

LACAN, Jacques. (1985). "La tópica de lo imaginario". En El Seminario. Libro 1. Los escritos técnicos de Freud 1953-1954 (119-140; Rithee Cevasco, Trad.). Paidós.

LACAN, Jacques. (2005). "La instancia de la letra en el inconsciente o la razón desde Freud”. En: Escritos (Vol. 1, 473-510; Tomás Segovia y Armando Suárez, Trads.). Siglo XXI.

LÓPEZ DE LiZAGA, José Luis. (2008). "La ética del discurso y el concepto kantiano de deberes hacia uno mismo". Estudios de Filosofia, (38), 103-120.

PINZÓN, Ivonne Natacha. (2019). "La inconsumada moral de esclavo en la sociedad del rendimiento". Cuadernos del CLAEH. Revista Uruguaya de Ciencias Sociales, 38(110), 301-310. https://doi.org/10.29192/CLAEH.38.2.13

RECiO SASTRE, Alejandro. (2019). "Análisis crítico sobre las nociones de poder y de piscopolítica en el pensamiento de Byung-Chul Han". Revista Scientific, 4(13), 241-259. https://doi.org/10.29394/Scientific.issn.2542-2987.2019.4.13.12.240-260

SAUSSURE, Ferdinand. (1945). Curso de lingüística general (Amado Alonso, Trad.). Losada.

STAVRAKAKIS, Yannis. (2007). Lacan y lo político (Luis Barbieri y Martin Valiente, Trads.). Prometeo Libros. 